\title{
Simultaneous Optimization of Oral and Transdermal Nanovesicles for Bioavailability Enhancement of Ivabradine Hydrochloride
}

\author{
Marianne Joseph Naguib iD ' \\ Ibrahim Elsayed (iD 1,2 \\ Mahmoud Hassan Teaima (iD \\ 'Department of Pharmaceutics and \\ Industrial Pharmacy, Faculty of Pharmacy, \\ Cairo University, Cairo, Egypt; \\ ${ }^{2}$ Department of Pharmaceutical Sciences, \\ College of Pharmacy and Thumbay \\ Research Institute for Precision Medicine, \\ Gulf Medical University, Ajman, United \\ Arab Emirates
}

Correspondence: Marianne Joseph Naguib Department of Pharmaceutics and Industrial Pharmacy, Faculty of Pharmacy, Cairo University, Cairo, Egypt

Email marian.naguib@pharma.cu.edu.eg
Purpose: Ivabradine hydrochloride is selective pacemaker current $\left(\mathrm{I}_{\mathrm{f}}\right)$ ion channel inhibitor used in case of chronic heart failure (CHF) with superior efficacy and lower side effects than most $\beta$-blockers. However, the drug suffers from low bioavailability $(\approx 40 \%)$ due to extensive first-pass metabolism. Hence, this work aims to formulate nanovesicular platforms to enhance their bioavailability both orally and transdermally.

Materials and Methods: A central composite face-centered design was employed to formulate the nanovesicles, both phosphatidylcholine: drug ratio and percentage of pluronic F68 were used as independent variables. The nine developed formulae were characterized in terms of vesicle size $(\mathrm{nm})$, polydispersity index, zeta potential $(\mathrm{mV})$, entrapment efficiency (\%). Decreasing vesicle size, increasing negative value of the zeta potential, and increasing entrapment efficiency were the chosen constraints to optimize the engineered nanovesicles. The candidate formula was subjected to further investigation including lyophilization, loading into carbopol gel, in vitro release, imaging with a transmission electron microscope, histopathological examination, in vitro cytotoxicity study and in vivo pharmacokinetics.

Results: The optimized nanovesicular formula was composed of lipid: drug ratio of 3.91:1 and $100 \%$ pluronic as a stabilizer. It has particle size, zeta potential and entrapment efficiency of $337.6 \mathrm{~nm},-40.5 \mathrm{mV}$ and 30.5 , respectively. It was then lyophilized in the presence of $5 \%$ trehalose as a cryoprotectant, dispersed in $0.5 \%$ carbopol to develop the transdermal gel. The two different forms of the candidate formula (lyophilized and gel form) displayed sustained drug release in comparison to drug solution. The histopathological and cytotoxicity studies showed that the optimized formula was safe and highly biocompatible. The pharmacokinetics parameters measured declared a higher $\mathrm{C}_{\max }$ and half-life of both formulae in comparison to market product $\left(\right.$ Procoralan ${ }^{\circledR}$ ) with a 2.54 - and 1.85 -folds increase in bioavailability, respectively.

Conclusion: Hence, the developed nanovesicles can be reported as the first nanoplatforms to be used for simultaneous ivabradine delivery by both oral and topical routes with enhanced oral and transdermal drug delivery. The developed nanoplatforms hence can be further used to formulate other drugs that suffer from low bioavailability due to extensive first-pass metabolism.

Keywords: ivabradine, oral, transdermal, central composite, lyophilized, extensive first pass

\section{Introduction}

Chronic heart failure (CHF) is a critical and serious disease affecting up to $3 \%$ of the peoples in advanced countries. ${ }^{1}$ Reducing the heart rate $(<70$ beats per $\min )$ is highly desired to reduce mortality in CHF patients. Ivabradine was first authorized by the European Medicines Agency in 2005 and then approved by the United 
States Food and Drug Administration in 2015. ${ }^{2,3}$ It acts as a selective inhibitor to the $\mathrm{I}_{\mathrm{f}}$ ion channels of the sinoatrial node which leads to lowering the heart rate without affecting the cardiac conductivity and repolarization. ${ }^{4}$ Moreover, it is superior over $\beta$-blockers in being more effective with fewer side effects, in addition to being capable of improving exercise tolerance. ${ }^{5}$ The drug has excellent physicochemical characteristics including its high solubility $(50 \mathrm{mg} / \mathrm{mL})$, suitable partition coefficient (3.17) and small molecular weight (468.6 g/mol). ${ }^{6,7}$ Unfortunately, ivabradine has significantly low oral bioavailability $(\approx 40 \%$ ) due to its extensive first-pass metabolism that yields inactive metabolites. ${ }^{8}$ Ivabradine is a substrate for the CYP3A4 enzyme system which is mainly present in the gut and the liver. The only active metabolite is $\mathrm{N}$-demethylated derivative which is formed in an amount equivalent to $40 \%$ of the parent compound. ${ }^{7}$ Moreover, it suffers from a rapid elimination rate with a significantly short elimination half-life $(2 \mathrm{~h})$ but still its dose (2.5-7.5 mg) and dosing frequency (two times daily) remain acceptable and does not affect patient compliance. ${ }^{9}$

To avoid the extensive first-pass effect, several trials were performed to deliver ivabradine with different routes that could avoid passing through the small intestine including transdermal and buccal applications. ${ }^{10,11}$ Ivabradine was loaded into transdermal patches composed of hydroxypropyl methylcellulose K15 and ethyl cellulose $(2: 1 \mathrm{w} / \mathrm{w})$. These patches achieved a controlled release and sustained pharmacokinetic profile after application on Wistar rat skin. ${ }^{12}$ Propylene glycol, isopropyl myristate and oleic acid were incorporated by Banu et al into the transdermal patches to further enhance the drug permeation. ${ }^{13}$ Recently, Balata et al developed transfersomes loaded with ivabradine utilizing either tween 80 , sodium lauryl sulfate or cetrimide as stabilizers and permeation enhancers mixed in different ratios with the drug and phospholipid. ${ }^{6}$ The optimized transfersomal formula was incorporated into a film composed of hydroxypropyl methylcellulose and starch in ratio $1: 1 \mathrm{w} / \mathrm{w}$. The developed nanostructured transdermal film showed improved permeability and retention compared to the unformulated ivabradine. On the other hand, Lodhi et al tried to develop mucoadhesive buccal films loaded with ivabradine. ${ }^{14}$ The developed buccal films showed a good ex vivo permeation through the porcine buccal membrane, but the study lacked the comparison with the pure drug as a reference.
This study aimed to develop and optimize lipid-based nanovesicles loaded with ivabradine and stabilized by either Pluronic F68, span 60 or a mixture of both with different ratios. These nanovesicles could be able to increase the extent of drug absorption after oral administration through bypassing the hepatic uptake and metabolism due to their built-in lipophilicity and small particle size. ${ }^{15,16}$ Moreover, the developed nanovesicles were embedded in a gel and then topically applied to ensure their abilities to enhance the transdermal permeation of ivabradine depending on the utilized surfactants that could act as potential permeation enhancers. ${ }^{17,18}$ The excipients used to develop the nanovesicles are significantly cheaper than polylactic co-glycolic acid and D- $\alpha$-tocopherol polyethylene glycol 1000 succinate used in a previous study. Moreover, developing a single formulation for both oral and transdermal delivery of drugs could save time and effort, and facilitate the way for developing a universal formulation for a wide range of applications.

\section{Materials}

Ivabradine hydrochloride was supplied by Eva Pharma, Cairo, Egypt. Cholesterol was purchased from Acros Organics, NJ, USA. Phosphatidylcholine (PC), Pluronic F68 (PL) and span 60 (SP) were purchased from SigmaAldrich, St. Louis, MO, USA. The remaining chemicals and solvents were of analytical grade used without further processing or purification.

\section{Experimental Design}

The study was fully designed by Design Expert ${ }^{\mathrm{TM}}$ software (ver. 7; Stat-Ease Inc., MN, USA) with a central-composite response-surface statistical analysis. PC was utilized as a builder for the nanovesicular walls in different ratios to the drug starting from $0.5: 1 \mathrm{w} / \mathrm{w}$ to $4: 1 \mathrm{w} / \mathrm{w}$ (A: PC/D). Moreover, SP and PL were used as stabilizers in different ratios with a total amount of $200 \mathrm{mg}$ (B: PL\%: 0-100\%). On the other hand, the vesicle size $\left(\mathrm{Y}_{1}\right)$ of the prepared nanovesicles was measured along with their polydispersity index $\left(\mathrm{Y}_{2}\right)$, zeta potential $\left(\mathrm{Y}_{3}\right)$ and entrapment efficiency $\left(\mathrm{Y}_{4}\right)$. The composition and all measured responses of the prepared nanovesicles are listed in Table 1. The statistical models were validated through the determination of their $\mathrm{R}^{2}$, lack of fit and adequate precision. A difference less than 0.2 between the adjusted and the predicted $\mathrm{R}^{2}$ values, a nonsignificant lack of fit and an adequate precision of more than 4 could indicate the capability of the model to predict vales and navigate the design space with a minimal lack of fit. ${ }^{19-22}$ 
Table I Experimental Runs, Independent Variables and Measured Responses of Ivabradine Nanovesicles Following a Central Composite Design ${ }^{\mathrm{a}, \mathrm{b}}$

\begin{tabular}{|c|c|c|c|c|c|c|}
\hline Formulae & $\begin{array}{l}\text { PC/D } \\
\text { Ratio }^{c}\end{array}$ & $\begin{array}{l}\text { PL } \\
\%\end{array}$ & Vesicle Size (nm) & $\begin{array}{l}\text { Polydispersity } \\
\text { Index }\end{array}$ & $\begin{array}{l}\text { Zeta Potential } \\
(\mathrm{mV})\end{array}$ & $\begin{array}{c}\text { Entrapment Efficiency } \\
(\% \mathrm{w} / \mathrm{w})\end{array}$ \\
\hline $\mathrm{NI}$ & 0.5 & 0 & $1615.5 \pm 8.3$ & $0.801 \pm 0.03$ & $-32.85 \pm 1.4$ & $24.82 \pm 1.1$ \\
\hline N2 & 0.5 & 50 & $1383.0 \pm 3.1$ & $0.807 \pm 0.01$ & $-34.28 \pm 2.7$ & $16.27 \pm 1.8$ \\
\hline N3 & 0.5 & 100 & $545.7 \pm 1.8$ & $0.609 \pm 0.05$ & $-35.70 \pm 2.1$ & $6.48 \pm 0.4$ \\
\hline N4 & 2.25 & 0 & $610.0 \pm 2.7$ & $0.676 \pm 0.02$ & $-40.15 \pm 3.9$ & $31.14 \pm 3.9$ \\
\hline \multirow[t]{5}{*}{ N5 } & \multirow[t]{5}{*}{2.25} & \multirow[t]{5}{*}{50} & $659.7 \pm 3.0$ & $0.714 \pm 0.02$ & $-40.80 \pm 0.5$ & $21.61 \pm 1.6$ \\
\hline & & & $613.0 \pm 3.6$ & $0.728 \pm 0.00$ & $-41.85 \pm 0.6$ & $21.79 \pm 1.2$ \\
\hline & & & $486.2 \pm 0.8$ & $0.561 \pm 0.04$ & $-39.85 \pm 1.0$ & $21.46 \pm 2.5$ \\
\hline & & & $539.2 \pm 4.2$ & $0.513 \pm 0.01$ & $-39.80 \pm 0.6$ & $27.33 \pm 0.3$ \\
\hline & & & $500.0 \pm 6.2$ & $0.600 \pm 0.07$ & $-40.00 \pm 0.8$ & $24.00 \pm 0.1$ \\
\hline N6 & 2.25 & 100 & $216.0 \pm 1.5$ & $0.702 \pm 0.01$ & $-38.85 \pm 1.8$ & $14.57 \pm 2.0$ \\
\hline N7 & 4 & 0 & $575.5 \pm 7.9$ & $0.598 \pm 0.00$ & $-42.20 \pm 1.5$ & $31.78 \pm 1.1$ \\
\hline N8 & 4 & 50 & $513.3 \pm 8.8$ & $0.608 \pm 0.05$ & $-43.28 \pm 3.3$ & $30.16 \pm 3.7$ \\
\hline N9 & 4 & 100 & $352.9 \pm 0.7$ & $0.679 \pm 0.03$ & $-40.05 \pm 3.1$ & $33.47 \pm 1.7$ \\
\hline
\end{tabular}

Notes: ${ }^{a}$ All the formulae prepared using $100 \mathrm{mg}$ of ivabradine. ${ }^{b}$ Values are expressed as mean $\pm \mathrm{SD} ; \mathrm{n}=3 .{ }^{\mathrm{c}}$ Cholesterol is added at a constant percent of PC $(5 \%)$.

\section{Preparation of Ivabradine Nanovesicles}

The ivabradine nanovesicles were prepared by the coacervation phase separation method. ${ }^{23,24} \mathrm{SP}$, PL, PC, cholesterol $(5 \% \mathrm{w} / \mathrm{w}$ of PC), and ivabradine $(100 \mathrm{mg})$ were accurately weighed and dissolved in $0.25 \mathrm{~mL}$ absolute ethanol in a stoppered $10 \mathrm{~mL}$ glass vial. Then, the vial was incubated in a thermostatic shaking water bath with the temperature adjusted at $60{ }^{\circ} \mathrm{C}$ and a stirring rate of $1000 \mathrm{rpm}$ for at least $5 \mathrm{~min}$ to ensure that all ingredients were completely dissolved. Afterward, distilled water $(0.1 \mathrm{~mL})$, preheated at $60{ }^{\circ} \mathrm{C}$, was added and mixed with the alcoholic solution on the same water bath until a clear mixture was formed. Finally, the prepared formulae were allowed to cool down to room temperature before being stored in the refrigerator at $4{ }^{\circ} \mathrm{C}$ until further characterization.

\section{Evaluation of Ivabradine Nanovesicles Determination of the Vesicle Size, Polydispersity Index and Zeta Potential}

Zetasizer Nano ZS (Malvern Panalytical Ltd, Malvern, UK) adopting the dynamic light scattering technique was employed to measure the vesicle size of the prepared ivabradine nanovesicles. Before analysis, each formula was hydrated with $10 \mathrm{~mL}$ distilled water in a bath sonicator (Clifton $^{\mathrm{TM}}$ Heated Timed Ultrasonic Bath, Nickel Electro Ltd, Weston-super-Mare, UK) and then, a $1 \mathrm{~mL}$ sample was transferred to a folded capillary zeta cell to measure the vesicle size, polydispersity index and zeta potential. All measurements were performed thrice at $25{ }^{\circ} \mathrm{C}$ with a count rate of 200-400 kilo counts per second (Kcps) and the mean values \pm standard deviations were recorded in Table 1.

\section{Determination of the Entrapment Efficiency Percentages}

The amounts of ivabradine entrapped in the prepared nanovesicles were indirectly determined after diluting each formula with $10 \mathrm{~mL}$ distilled water and centrifuging it at $15,000 \mathrm{rpm}$ and a temperature $4{ }^{\circ} \mathrm{C}$ for $60 \mathrm{~min}$ in a cooling centrifuge (Mikro 200 R, Hettich Lab, Tuttlingen, Germany). The supernatant was then separated, diluted with distilled water, and spectrophotometrically analyzed at ivabradine $\lambda_{\max }(284 \mathrm{~nm})$. Finally, the entrapment efficiency percentages were calculated based on the following equation:

$$
\text { Entrapment efficiency }=\frac{T A-S A}{T A} X 100 \%
$$


where TA is the total amount of ivabradine in each formula while SA is the amount of ivabradine in the supernatant.

\section{Desirability and Optimization}

To statistically optimize the composition of the prepared ivabradine nanovesicles, the desirability values were calculated to find the formula with the lowest vesicle size, polydispersity index, and highest zeta potential and entrapment efficiency. ${ }^{25}$ The desirability value allows merging all the dependent responses in one measurement and concluding the superlative levels of the independent parameters. It is determined by first calculating each desirability function. ${ }^{26}$

Responses (Y) are maximized as follows

$$
d_{i}=\frac{Y i-Y_{\min }}{Y_{\max }-Y_{\min }}
$$

and minimized as follows

$$
D_{i}=\frac{Y_{\max }-Y i}{Y_{\max }-Y_{\min }}
$$

Where $Y_{\min }, Y_{\max }$ and $Y_{i}$ are the minimum, maximum, and individual response values, respectively.

The overall desirability values were calculated from the individual values by using the following equation for $n$ responses:

$$
\mathrm{D}=(\mathrm{d} 1 \times \mathrm{d} 2 \ldots \mathrm{dn})^{\frac{1}{n}}
$$

The formula with the optimum composition was prepared and subjected to the same characterization tests. The obtained findings were compared to the predicted values and the percentage errors were calculated to ensure the prediction capabilities of the employed statistical models. ${ }^{27,28}$

\section{Freeze-Drying of the Optimized Ivabradine Nanovesicles}

The optimized ivabradine nanovesicles were lyophilized either with and without mannitol or trehalose as cryoprotectants, each in a concentration of $2.5 \%$ and $5 \%$. The formulae were stored overnight in the freezer at a temperature $-20{ }^{\circ} \mathrm{C}$ and then, transferred to NovalypheNL 500 freeze-dryer (Savant Instruments Corp., NY, USA). The freeze-drying process continued for $24 \mathrm{~h}$ at a temperature of $-45{ }^{\circ} \mathrm{C}$ and a pressure of $7 \times 10^{-2}$ mbar. $^{29,30}$ The freeze-dried formulae were kept in a desiccator until being reconstituted with distilled water and investigated for their vesicle size, polydispersity index, zeta potential and entrapment efficiency. The new findings were compared to the respective results obtained before freeze-drying.

\section{Preparation and Characterization of Ivabradine Nanovesicular Gel}

The freeze-dried optimized ivabradine formula was reconstituted with $10 \mathrm{~mL}$ distilled water and then, carbopol 940 was added to the prepared nanodispersion to give a concentration of $0.5 \% \mathrm{w} / \mathrm{v}$. The mixture was stirred overnight to ensure hydration of carbopol before being converted to gel using tri-ethanolamine added in a ratio of $1: 1 \mathrm{w} / \mathrm{w}$ to carbopol. ${ }^{31,32}$ The prepared nanogel was characterized by studying its rheological properties.

Brookfield viscometer (Model No. HBDV-I, MA, USA) adopting a CPE-41 spindle was utilized to measure the viscosity and the shear stress $\left(\tau\right.$, dyne $\left./ \mathrm{cm}^{2}\right)$ of the prepared ivabradine gel at a different rate of shear $\left(\gamma, \mathrm{s}^{-1}\right)$, ranged from 2 to $100 \mathrm{rpm}$ within the acceptable ranges of torque percentages. The flow index (n) was calculated based on the power model (Eq. 5) and used to determine the flow behavior of the prepared nanogel if it is Newtonian $(\mathrm{n} \approx 1)$, shear-thinning $(n<1)$ or shear thickening $(n>1){ }^{33}$

$$
\tau=K \gamma^{n}
$$

where $\mathrm{K}$ is the consistency index $\left(\right.$ dyne $\left./ \mathrm{cm}^{2} \cdot \mathrm{s}^{\mathrm{n}}\right)$.

\section{In vitro Ivabradine Release}

The release profiles of ivabradine from the optimized nanovesicles, before and after freeze-drying and after gelling, were investigated and compared to the dissolution profile of the plain drug solution. A sample equivalent to $6 \mathrm{mg}$ ivabradine was withdrawn from each formula and placed in a dialysis bag with 12-14 kDa cut-off (SigmaAldrich, St. Louis, MO, USA) immersed in $25 \mathrm{~mL}$ phosphate buffer $\left(\mathrm{pH}\right.$ 7.4). ${ }^{34}$ The dissolution medium was stirred at $100 \mathrm{rpm}$ and heated at $37{ }^{\circ} \mathrm{C}$ for the drug solution, the optimized formula and the lyophilized one and at $35^{\circ} \mathrm{C}$ for the nanovesicular gel using a thermostatic shaking water bath (Model No. SBS40, Stuart, Staffordshire, UK). Samples of $1 \mathrm{~mL}$ each were withdrawn at the pre-planned time intervals; $0.25,0.5,1,2,3,4,6$ and $8 \mathrm{~h}$. The ivabradine concentrations in the withdrawn samples were measured using a UV spectrophotometer at $\lambda_{\max }$ of $284 \mathrm{~nm}$. The whole dissolution experiment was performed three times for each formula and the mean percentage dissolved \pm standard deviations were calculated and plotted against its respective time interval. The similarity 
factor $\left(f_{2}\right)$ was utilized to compare the ivabradine dissolution profiles after being calculated using the following equation: ${ }^{35,36}$

$$
f_{2}=50 \times \log \left\{\left[1+\left(\frac{1}{n}\right) \sum_{j=1}^{n}\left|R_{j}-T_{j}\right|^{2}\right]^{-0.5} \times 100\right\}
$$

where the percentages of ivabradine released at each time interval ( $\mathrm{j}$ ) were $\mathrm{R}$ and $\mathrm{T}$ for the reference and the test formulae, respectively, and the number of samples employed in the calculations was $\mathrm{n}$. The dissolution halflife $\left(\mathrm{T}_{50 \%}\right)$ values were calculated and utilized to compare the drug release profiles.

\section{Imaging of the Optimized Ivabradine Nanovesicles}

The optimized nanovesicles were visualized under JEM1230 transmission electron microscope (Jeol, Tokyo, Japan), operated at a voltage of $100 \mathrm{kV}$. Before imaging, sample was withdrawn, sprayed over a copper grid coated with carbon, stained with $2 \%$ phosphotungstic acid and finally, dried at room temperature.

\section{Effect of Storage on Ivabradine Lyophilized Nanovesicles}

The lyophilized formula (L5) was assessed following storage in a cold place (refrigerator $2-8{ }^{\circ} \mathrm{C}$ ) for six months. ${ }^{37}$ At the end of the storage period, the lyophilized nanovesicles were evaluated for their appearance, vesicle size, polydispersity index, zeta potential and entrapment efficiency. Statistical analysis of the obtained results was performed by Student's $t$-test using SPSS 17.0 software (SPSS Inc., Chicago, IL). Difference at $p$-value $<0.05$ was considered significant.

\section{Histopathological Examination}

To assess the possible irritation effect of the prepared lyophilized nanovesicular gel, the nanovesicular gel formula was applied to shaved back skin of a rabbit in an area of $5 \mathrm{~cm}^{2}$ diameter for three consecutive days. Another area was shaved and left untreated as a control. Afterward, the rabbit was euthanized, skin samples from treated and untreated areas were collected, and stored in 10\% formalin. The samples were then dehydrated using ethanol, fixed in paraffin and stained with eosin and hematoxylin. Sections of $5 \mu \mathrm{m}$ were cut using a microtome and examined under a light microscope. ${ }^{25}$

\section{In vitro Cytotoxicity Study}

In flat bottom 96 well-microplates, HepG2 cells (Human liver adenocarcinoma cells) $\left(0.5 \times 10^{5}\right)$ were cultured in $180 \mu \mathrm{L} /$ well RPMI media supplemented with $10 \%$ fetal bovine serum, $2 \mu \mathrm{mol} / \mathrm{mL}$ L-glutamine, $250 \mathrm{ng} / \mathrm{mL}$ fungizone, 100 units $/ \mathrm{mL}$ penicillin-streptomycin solutions at $37^{\circ} \mathrm{C}$ in a $\mathrm{CO}_{2}$ incubator. ${ }^{38,39}$ The plates were incubated for $24 \mathrm{~h}$ at $37^{\circ} \mathrm{C}$ in a humidified $5 \% \mathrm{CO}_{2}$ atmosphere to allow cells to settle down. After incubation, the media were removed, and $180 \mu \mathrm{L} /$ well fresh serum-free medium was added to each well. Cells are then treated with $20 \mu \mathrm{L}$ of different concentrations of either the drug solution or the lyophilized nanovesicular formula $(500-15.62 \mu \mathrm{M})$. The plates were then incubated for $24 \mathrm{~h}$ at $37^{\circ} \mathrm{C}$ in a humidified $5 \% \mathrm{CO}_{2}$ atmosphere. After incubation, the media were removed and MTT solution $40 \mu \mathrm{L} /$ well was added and incubated for an additional $4 \mathrm{~h}$. MTT crystals were solubilized by adding acidified isopropanol (160 $\mu \mathrm{L} /$ well) and the plate was shaken at room temperature. This was followed by photometric determination of the absorbance at $570 \mathrm{~nm}$ using the microplate ELISA reader (FLUOstar Omega, BMG, Labtech, Germany). The absorbance of the resulting color is directly proportional to the number of viable cells in each sample. The percentage of relative viability was calculated using the following equation:

$$
\text { Percentage of relative vability }=\frac{\begin{array}{l}
\text { Absorbance of } \\
\text { treated cells }
\end{array}}{\begin{array}{l}
\text { Absorbance of } \\
\text { control cells }
\end{array}} \text { X100 }
$$

Statistical analysis was done for both drug solution and lyophilized nanovesicles in comparison to normal untreated cells using Student's $t$-test employing SPSS 17.0 software (SPSS Inc., Chicago, IL). The difference at $p$-value $<0.05$ was considered significant.

\section{Oral and Transdermal Bioavailability of Ivabradine}

\section{Animals}

Nine New Zealand male rabbits $(2-3 \mathrm{~kg}$ each) were involved in the study. Each rabbit was hosted in a separate cage where the humidity and temperature were maintained at $55 \pm 5 \%$ and $22 \pm 2{ }^{\circ} \mathrm{C}$, respectively. Equal daily cycles of light and dark circumstances were maintained according to the Guide for the Care and Use of Laboratory Animals. ${ }^{40}$ 


\section{Study Design}

The procedure was reviewed and approved by the ethical committee of Faculty of Pharmacy, Cairo University with an application number of PI 2653. The rabbits were randomly assigned to three groups where the first group administered ivabradine market product (Procoralan ${ }^{\circledR}$ ) and the second group administered the freeze-dried optimized nanovesicles orally while the optimized nanovesicular gel was applied to the shaved back skin of the rabbits assigned to the third group. A randomized three-period crossover design was applied to eliminate subject-tosubject variation with a washout period of a week. ${ }^{41}$ The administered dose $(0.26 \mathrm{mg} / \mathrm{kg})$ was calculated from the human dose after an adjustment based on the difference in the body surface area according to the following equation. $^{42}$

$$
\text { Animal dose }(m g / k g)=\text { Human dose }(m g / k g) x \frac{\text { Human } k_{m}}{\text { Animal } k_{m}}
$$

where

$$
k_{m}=\frac{\text { Average body weight }(\mathrm{kg})}{\text { Body surface area }\left(\mathrm{m}^{2}\right)}
$$

Blood samples, $2 \mathrm{~mL}$ each, were withdrawn from the tail vein at $0.25,0.5,0.75,1,1.5,2,4,6,8$ and $24 \mathrm{~h}$ following oral administration or topical application. Plasma was separated by centrifugation at $5000 \mathrm{rpm}$ at $5{ }^{\circ} \mathrm{C}$ for 20 min and stored in a freezer at $-20{ }^{\circ} \mathrm{C}$ until the time of analysis.

\section{Determination of Ivabradine in Plasma}

Plasma samples were thawed at room temperature and then mixed in a ratio of $10: 1 \mathrm{v} / \mathrm{v}$ with a $200 \mathrm{ng} / \mathrm{mL}$ alcoholic solution of the internal standard (clopidogrel). Ivabradine was extracted using methanol added in a ratio of $2: 1 \mathrm{v} / \mathrm{v}$ to the plasma samples. The extracted drug was dried under vacuum and reconstituted with a mobile phase composed of methanol and $0.2 \% \mathrm{w} / \mathrm{v}$ aqueous solution of formic acid mixed in a ratio of $7: 3 \mathrm{v} / \mathrm{v}$, respectively. The samples were injected into an LC/MS/MS (Shimadzu, Tokyo, Japan) equipped with a Poroshell column (120ECC18, 4.6 x $50 \mathrm{~mm}, 2.7 \mu \mathrm{m}$, Agilent Technologies, DE, USA) and a mobile phase running at a flow rate of $0.6 \mathrm{~mL} /$ min. The analysis method was validated with linearity $\left(\mathrm{R}^{2}\right.$ $=0.9998$ ) and a lower limit of detection of $0.2 \mathrm{ng} / \mathrm{mL}$. The equipment was operated with a positive ion mode, an accelerator cell voltage of $7 \mathrm{~V}$ and a dwell of 200 s. Ivabradine and clopidogrel were quantified at a precursor-to-product ion ratios of 469/177 and 322/212, respectively.

\section{Pharmacokinetic and Statistical Analysis}

The in vivo results were processed using noncompartmental pharmacokinetic analysis utilizing Kinetica ${ }^{\circledR}$ software (Version 5, Thermo Fisher Scientific Inc., MA, USA) to determine the key pharmacokinetic parameters including the maximum concentration of ivabradine in plasma $\left(\mathrm{C}_{\max }\right)$, its corresponding time $\left(\mathrm{T}_{\max }\right)$, the area under the curve from zero to the last time $A U C_{0}^{24}$, the area under the curve from zero to infinity $\left(A U C_{0}^{\infty}\right)$ and the relative bioavailability compared to the oral market product. The results were expressed as the mean of 9 rabbits \pm SD. The pharmacokinetic parameters were compared using the crossover ANOVA test. The nonparametric-signed ranks test (Wilcoxon) was used to compare the median values of $\mathrm{T}_{\max }$. A $p$-value $<0.05$ was considered statistically significant. Statistical analysis was performed using SPSS $19.0^{\circledR}$.

\section{Results and Discussion}

\section{Evaluation of Ivabradine Nanovesicles Determination of the Vesicle Size, Polydispersity Index and Zeta Potential}

The vesicle size of the prepared ivabradine nanovesicles ranged from 216.0 (N6) to 1615.5 (N1) nm, as shown in Table 1 and Figure 1A. The results were subjected to statistical analysis using a quadratic model after being converted to their square root values to increase the validity of the statistical analysis. ${ }^{43,44}$ The model was assessed for its capability to cover the design space with an adequate precision of 23.32 and a limited gap between the adjusted (0.9502) and predicted (0.8596) $\mathrm{R}^{2}$ values, ie less than $0.2{ }^{45}$ Moreover, the model was statistically fitting the vesicle size values with a non-significant lack of fit $(p$-value $=0.5309) .{ }^{46}$ The following quadratic equation correlates the vesicle size findings with the studied independent parameters:

$$
\sqrt{\mathrm{Y}_{1}}=23.54-5.89 \mathrm{~A}-5.34 \mathrm{~B}+2.91 \mathrm{AB}+6.59 \mathrm{~A}^{2}-3.64 \mathrm{~B}^{2}
$$

Significant inverse relationships were observed between the two independent factors, ie PC/D ratio and PL\%, and the vesicle size with $p$-values $<0.001$. The effect of PC was clear at the low level of PL where SP was the predominant component inside the prepared nanovesicles. SP nanovesicles have more tendency to aggregate than the corresponding liposomal structures that are mainly built 

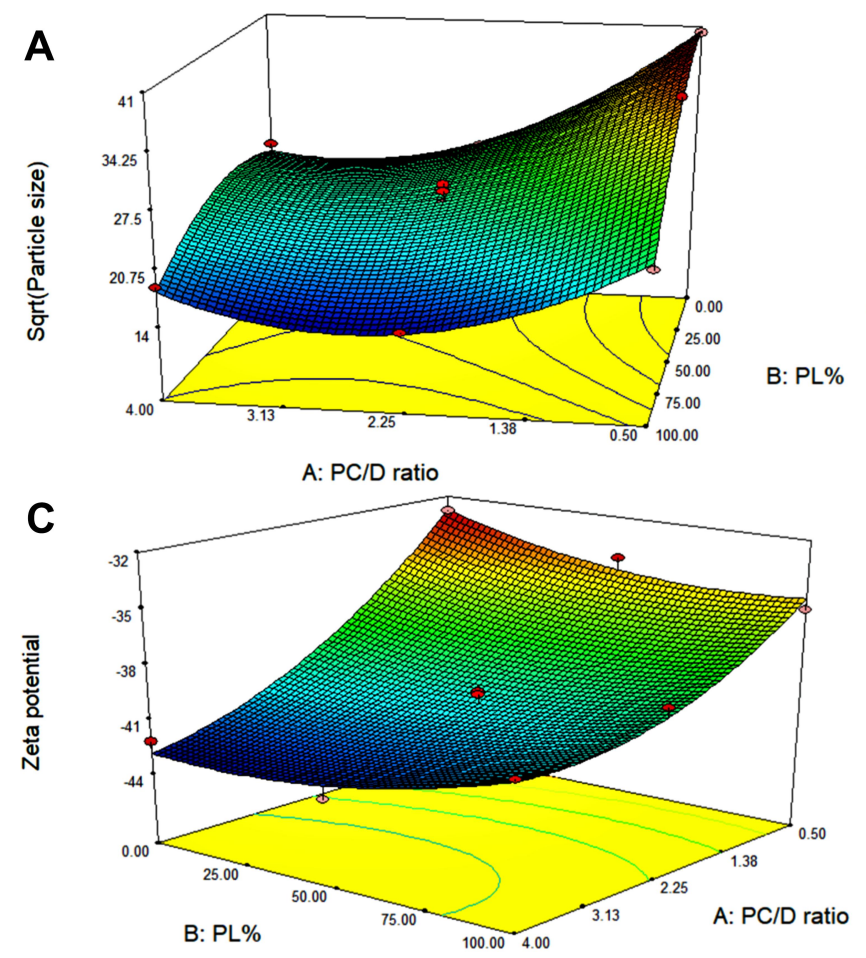

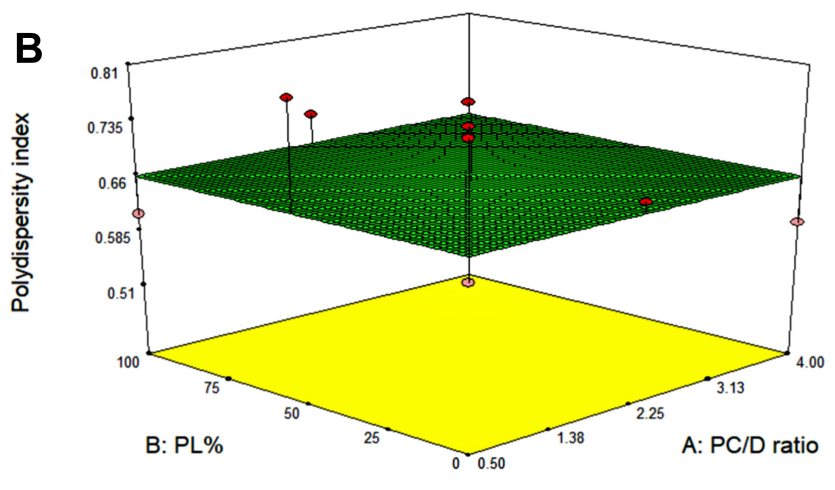

D

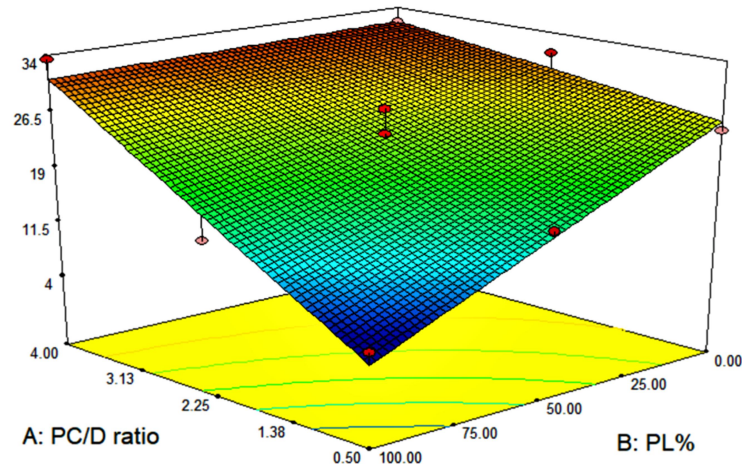

Figure I Three-dimensional response surface plots for the effects of PC/D $\left(X_{1}\right)$ and PL\% $\left(X_{2}\right)$ ratios on the vesicle size $(\mathbf{A})$, polydispersity index (B), zeta potential $(\mathbf{C})$ and entrapment efficiency $(\mathbf{D})$ of the prepared ivabradine nanovesicles.

out of PC and cholesterol. ${ }^{47}$ Consequently, increasing PC and cholesterol could significantly reduce the size of the prepared nanovesicles. On the other hand, increasing PL\% significantly reduced the vesicle size due to its ability to reduce the surface tension between the lipophilic components, ie PC, SP and cholesterol, and the surrounding aqueous phase. $^{48,49}$

The polydispersity index of the prepared nanovesicles ranged from 0.512 to 0.806 , as shown in Table 1 and Figure 1B, indicating their polydisperse nature. This could be referred to the presence of a mixture of polymers that might have a tendency to separate and form two PCbased nanovesicles and PL-based micelles. A similar coexistence of micelles and liposomes was previously reported and imaged by Ogunsola et al. ${ }^{50}$ The studied factors had no statistically significant effect on the polydispersity values as confirmed by the high $p$-value (0.7786).

The prepared nanovesicles had highly repulsive surfaces due to their zeta potential values which ranged from -32.85 and $-43.28 \mathrm{mV}$, as shown in Table 1 and Figure $1 \mathrm{C}$. The obtained values were found to be fitting the quadratic model with a $p$-value of 0.002 . The model had been assessed for its capability to predict the zeta potential upon modulating the studied factors via calculating its adequate precision (16.68), adjusted (0.9178) and predicted $(0.7441) \mathrm{R}^{2}$ values. The following equation correlates the zeta potential values with the two investigated factors:

$$
\mathrm{Y}_{3}=-40.48-3.78 \mathrm{~A}+0.10 \mathrm{~B}+1.25 \mathrm{AB}+1.74 \mathrm{~A}^{2}+1.02 \mathrm{~B}^{2}
$$

Based on the factorial ANOVA, the PC/D ratio had a statistically significant effect on the zeta potential values ( $p$-value $<0.0001)$ where the latter decreased by increasing PC. This could be logically attributed to the negative charge on the PC surfaces that could increase the negative value of the zeta potential which is mathematically considered a decrease. ${ }^{51}$ On the other hand, PL\% had no statistically significant effect on the zeta potential values and this might be referred to the non-ionic nature of the two incorporated surfactants. ${ }^{52}$

\section{Determination of the Entrapment Efficiency Percentages}

The drug entrapment percentages within the prepared nanovesicles ranged from 6.48 to $33.47 \%$, as shown in Table 1 and Figure 1D. This range was considered relatively low compared to the values obtained by Sharma 
et al (55.3-74.9\%) who prepared ivabradine polymeric nanoparticles. These nanoparticles were prepared using the $\mathrm{w} / \mathrm{o} / \mathrm{w}$ emulsification technique which could prevent the drug migration to the external aqueous phase during preparation and consequently yielded high entrapment efficiency. ${ }^{53} \mathrm{~A}$ two-factor interaction was adopted to statistically analyze the entrapment efficiency values with a $p$-value $<0.0001$. The model had a significantly high adequate precision (19.88) and a difference of less than 0.2 between the adjusted and predicted $\mathrm{R}^{2}$ values. The effects of the studied factors on the entrapment efficiency were established based on the following equation:

$$
\mathrm{Y}_{4}=23.45+7.79 \mathrm{~A}-5.54 \mathrm{~B}+5.01 \mathrm{AB}
$$

Opposite impacts on the entrapment efficiency values were observed upon increasing PC and PL with $p$-values of $<$ 0.0001 and 0.0004 , respectively. The entrapment efficiency was directly proportional with the PC ratio while it was inversely proportional with the PL\%. Increasing PC could enhance the formation of multilamellar nanovesicles which might be able to entrap more ivabradine within their layered membranes. ${ }^{54}$ On the other hand, increasing PL\% could increase the possibility of micellar formation to which a part of the drug might be partitioned from the original nanovesicles. ${ }^{50}$

\section{Desirability and Optimization}

The relation between the desirability values and the studied independent factors is demonstrated in Figure 2. The optimized nanovesicular formula was composed of PC in a ratio of $3.91: 1 \mathrm{w} / \mathrm{w}$ to the drug, cholesterol $(20 \mathrm{mg})$, in addition to $200 \mathrm{mg}$ PL as the only stabilizer without SP. This composition had the highest desirability value $(0.869)$

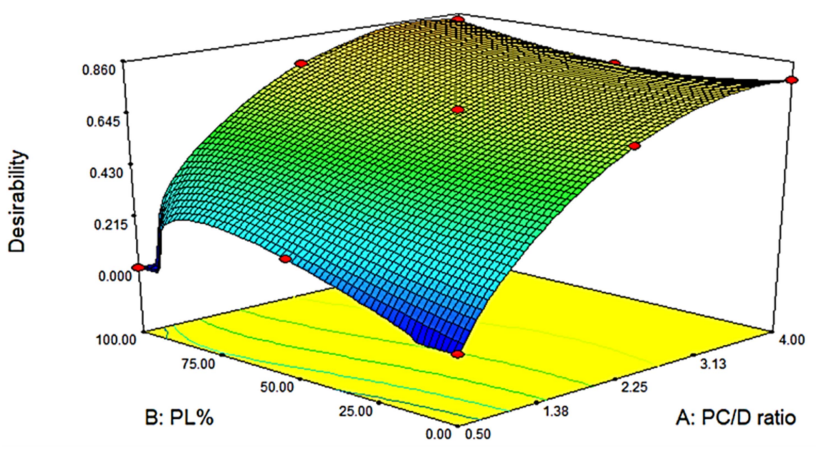

Figure 2 Three-dimensional response surface plot for the effects of PC/D $\left(X_{1}\right)$ and $\mathrm{PL} \%\left(\mathrm{X}_{2}\right)$ ratios on the desirability of the prepared ivabradine nanovesicles. calculated based on the optimization criteria fed into Design Expert ${ }^{\mathrm{TM}}$ software, ie the lowest vesicle size, the highest negative value of the zeta potential and the highest entrapment efficiency. The statistical model predicted that the optimized nanovesicular formula would have vesicle size, zeta potential and entrapment efficiency of 326.53 $\mathrm{nm},-40.19 \mathrm{mV}$ and $30.21 \%$. After preparing the formula and measuring its physical characteristics (vesicle size, zeta potential and entrapment efficiency), the actual findings ( $337.6 \mathrm{~nm},-40.5 \mathrm{mV}$ and $30.5 \%$ ) were found to be in a harmony with the predicted values with deviation percentages of less than $\pm 10 \%$.

\section{Characterization of the Freeze-Dried Optimized Ivabradine Nanovesicles}

After lyophilization, all formulae were reconstituted to their original volume with sonication for $2 \mathrm{~min}$. Samples were taken from each formula to identify the effects of different cryoprotectants on retaining the original characteristics of the optimized nanovesicular dispersion. Maintaining vesicle size was the main role of the added cryoprotectants through avoidance of the nanovesicular aggregation during lyophilization. ${ }^{55,56}$ As shown in Table 2, Formula L5 containing 5\% trehalose showed lower vesicle size to the optimized formula before lyophilization, where the entrapment efficiency was not statistically significant in comparison to the optimized formula without cryoprotectant (L1) and higher than other cryoprotectants used (L2, L3, L4). Trehalose was commonly considered as one of the best cryoprotectants used to preserve the size of different nanoparticles during lyophilization. ${ }^{57}$ Similar results were reported by Campos et al during the lyophilization of nimesulide solid lipid nanoparticles and by Siri et al during the lyophilization of albumin nanoparticles. ${ }^{58,59}$ Finally, the formula L5 was selected to be orally administered by the rabbits during the bioavailability study. It is worth mentioning that Bosch et al proved that trehalose prevents the aggregation of exosomes, where vesicle size showed a significant decrease after lyophilization in the presence of trehalose. ${ }^{60}$

\section{Characterization of Ivabradine Nanovesicular Gel}

The nanovesicular gel had a viscosity of $120,000 \mathrm{cp}$ which abruptly reduced by increasing the rate of shear, as shown in Figure 3. This indicated a non-Newtonian pseudoplastic flow behavior confirmed by the power low model that had a flow index ( $\mathrm{n}$ value) of 0.1321 . Carbopol is a common gelling 
Table 2 Effect of Lyophilization on Vesicle Size, Zeta Potential, Polydispersity Index and Entrapment Efficiency of Ivabradine Nanovesicles ${ }^{\mathrm{a}}$

\begin{tabular}{|l|c|c|c|c|c|c|}
\hline Formulae & $\begin{array}{c}\% \\
\text { Cryoprotectant }\end{array}$ & $\begin{array}{c}\text { Cryoprotectant } \\
\text { Type }\end{array}$ & $\begin{array}{c}\text { Vesicle Size } \\
\mathbf{( n m})\end{array}$ & $\begin{array}{c}\text { Zeta Potential } \\
\mathbf{( m V} \text { ) }\end{array}$ & $\begin{array}{c}\text { Polydispersity } \\
\text { Index }\end{array}$ & $\begin{array}{c}\text { Entrapment } \\
\text { Efficiency (\%) }\end{array}$ \\
\hline LI & 0 & - & $387.0 \pm 32.43$ & $-35.80 \pm 0.42$ & $0.466 \pm 0.09$ & $28.27 \pm 3.36$ \\
L2 & 2.5 & Mannitol & $537.4 \pm 12.50$ & $-36.35 \pm 2.05$ & $0.634 \pm 0.11$ & $22.12 \pm 2.12$ \\
L3 & 5 & Mannitol & $426.9 \pm 47.80$ & $-33.50 \pm 1.84$ & $0.511 \pm 0.10$ & $21.54 \pm 1.82$ \\
L4 & 2.5 & Trehalose & $426.3 \pm 18.67$ & $-33.75 \pm 0.35$ & $0.623 \pm 0.20$ & $21.08 \pm 2.25$ \\
L5 & 5 & Trehalose & $195.7 \pm 8.49$ & $-36.70 \pm 0.71$ & $0.466 \pm 0.02$ & $24.46 \pm 1.72$ \\
\hline
\end{tabular}

Note: ${ }^{a}$ Values are expressed as mean $\pm \mathrm{SD} ; \mathrm{n}=3$.

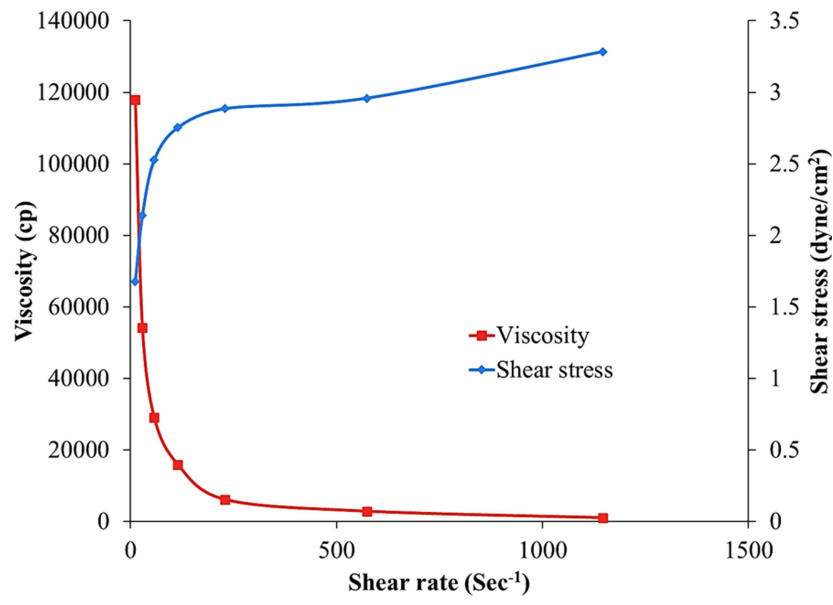

Figure 3 Rheological characteristics of the prepared nanovesicular gel.

agent and known to form a highly viscous shear-thinning gel. ${ }^{61}$ The high viscosity during storage is extremely useful to maintain the physical stability of the dispersed nanovesicles by hindering their aggregation. ${ }^{62}$ On the other hand, the gel viscosity will significantly drop-down during application and rubbing which will facilitate spreadability on the skin. ${ }^{63,64}$

\section{In vitro Ivabradine Release}

The study was conducted to determine the formulation effects on ivabradine release from the optimized nanovesicular formula as a dispersion, after lyophilization and after gelling. The drug release profiles are demonstrated in Figure 4. The drug release reached $100 \%$ in $2 \mathrm{~h}$, this suggested that the drug could freely diffuse through the dialysis bag. The percentages of ivabradine released from the optimized formula, lyophilized one and nanovesicular gel in $2 \mathrm{~h}$ were, $63.34 \% \pm 0.25,57.93 \% \pm 0.98$ and $38.59 \% \pm 0.84$, respectively. Those release profiles could indicate a fast initial drug release. A slower release was observed with the gel due to the high viscosity of the gel carrier that could slow down drug release. At the end of 8

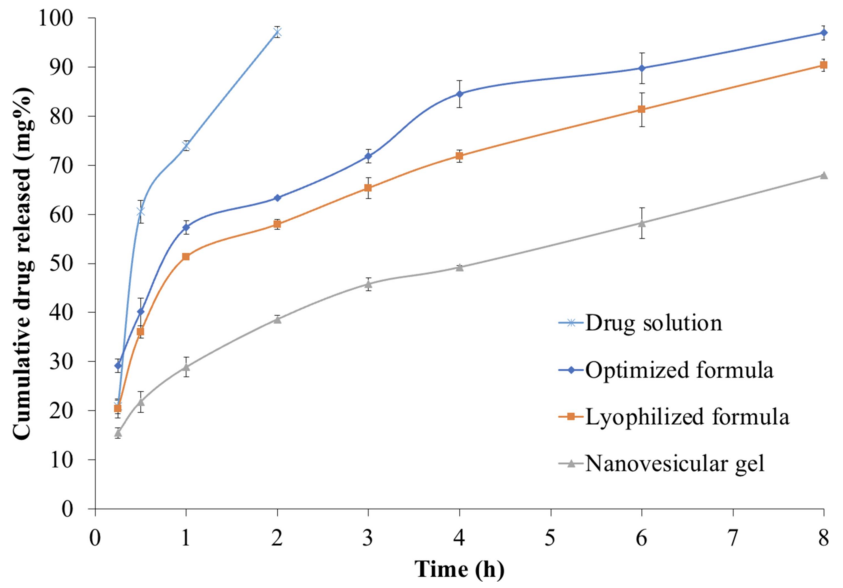

Figure 4 Ivabradine release profiles from the optimized formula before and after lyophilization and gelling, in comparison with the drug solution.

$h$, percentages of ivabradine released from the optimized formula, lyophilized one and nanovesicular gel were $96.96 \% \pm 1.45,90.36 \% \pm 1.27$ and $67.92 \% \pm 0.12$.

On the other hand and in terms of dissolution half-life $\left(\mathrm{T}_{50 \%}\right)$, the drug diffused from its solution through the dialysis membrane to the dissolution medium within 2 $\mathrm{h}\left(\mathrm{T}_{50 \%}=0.43 \mathrm{~h}\right)$ while it takes $8 \mathrm{~h}$ in the case of the optimized formula $\left(\mathrm{T}_{50 \%}=3.13 \mathrm{~h}\right)$ with $f 2$ value of 34 indicating the significant difference between the two release profiles. This might be due to the presence of several lipophilic components in the formula, ie PC, SP and cholesterol, which could be able to control the drug partitioning to the surrounding aqueous medium. ${ }^{65,66}$ Moreover, there was no difference between drug release profiles before and after lyophilization where the $f 2$ value was equal to 55 . On the other hand, converting the optimized formula to gel with carbopol led to a slower release profile $(f 2=29)$ and higher release $\mathrm{T}_{50 \%}(5.29 \mathrm{~h})$, compared to the optimized formula before gelling. Similar results were reported by Abdelnabi et al who prepared and optimized carbopol in situ nanovesicular gel loaded 
with buspirone hydrochloride. ${ }^{67}$ The slow drug release from the prepared nanovesicular gel was expected to give a sustained pharmacokinetic profile upon application to the skin. ${ }^{68}$

\section{Imaging of the Optimized Ivabradine Nanovesicles}

The optimized nanovesicles have been imaged under TEM, as shown in Figure 5. The nanovesicles appeared well dispersed with no clear aggregation (Figure 5A). Moreover, the nanovesicles had a smooth surface with an irregularly spherical outline (Figure 5B). The size of captured nanovesicles was in good correlation with the size determined using the light scattering dynamic technique (Figure 5B).

\section{Effect of Storage on Ivabradine Lyophilized Nanovesicles}

There was no change in the appearance of the stored lyophilized nanovesicles after six months. The measured vesicle size, polydispersity index, zeta potential and entrapment efficiency were $231.3 \mathrm{~nm} \pm 12.7,0.495 \pm$ $0.01,39.05 \mathrm{mV} \pm 2.75,25.84 \% \pm 1.03$. The statistical analysis using Student's $t$-test showed an absence of significance in the measured variables $(\mathrm{p}<0.05)$ compared to the original findings before storage. Similar results were declared by Soliman et al who formulated proniosomes containing the drug lacidipine and no significant difference was monitored after storage for 90 days. ${ }^{69}$

\section{Histopathological Examination}

The histopathological test was done on rabbit shaved back skin to assess the possible irritation effect of the applied nanovesicular gel. Microscopical examination for normal rabbit skin used as a negative control revealed normal epidermis, squamous epithelium, underlying dermis containing normal adnexa, hair follicles and sweat glands (Figure 6A). Upon application of the nanovesicular gel, no significant changes were monitored with epidermis, dermis or adnexa (Figure 6B). Also, no signs of inflammatory cell infiltration or any skin irritation were observed. These results declared the safety of the nanovesicular Carbopol gel for the transdermal delivery of ivabradine. ${ }^{70}$

\section{In vitro Cytotoxicity Study}

The results of the cytotoxicity are shown in Figure 7. Analysis of results revealed the absence of significance in cytotoxicity for both drug solution and lyophilized nanovesicular formula in comparison to normal untreated cells for concentrations equal to or less than $125 \mu \mathrm{g} / \mathrm{mL}$. Further increase in drug concentration revealed significant cytotoxicity. However, no significant differences were observed between the drug solution and the lyophilized nanovesicular formula. These results are in accordance

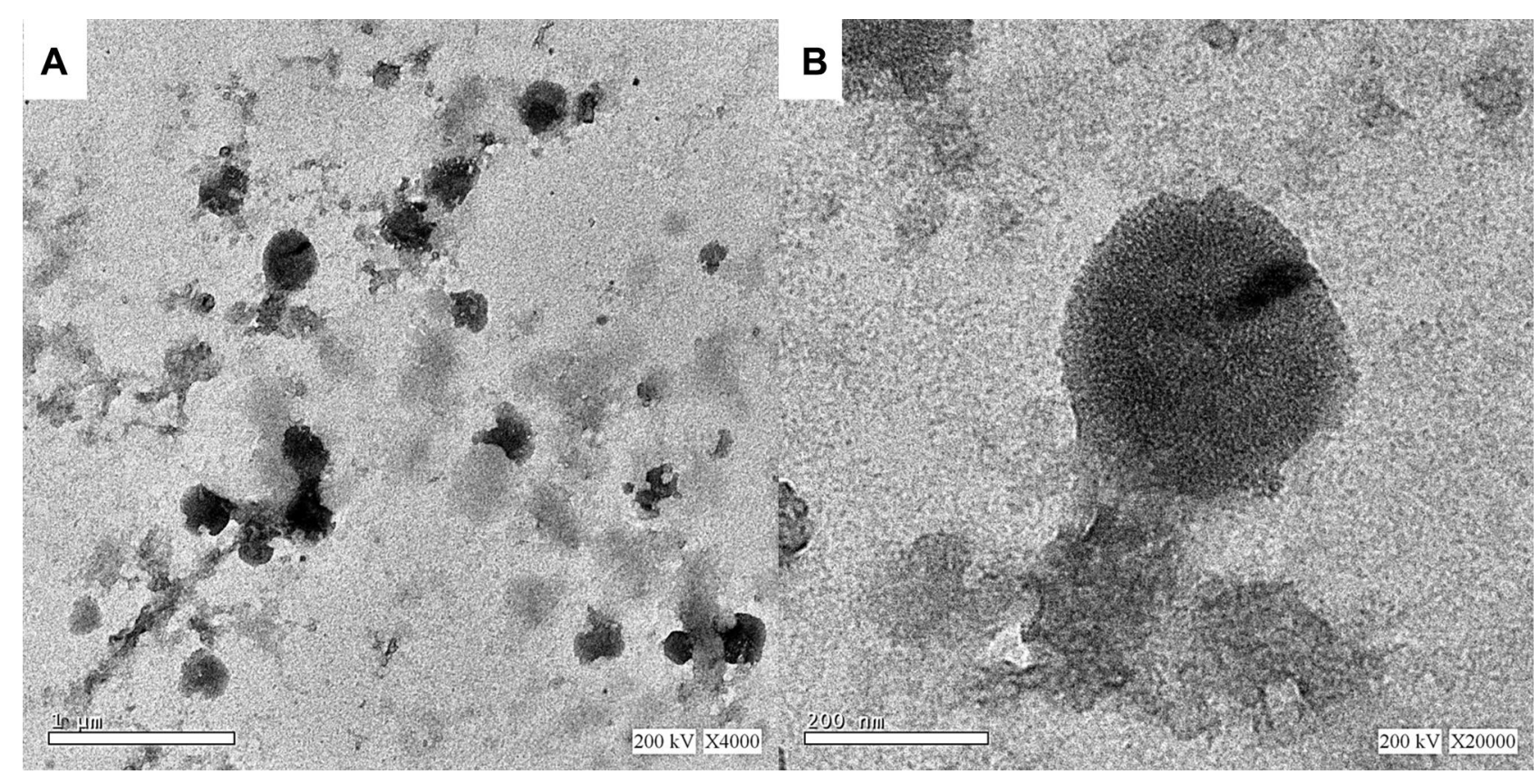

Figure 5 Transmission electron micrographs of the optimized ivabradine nanovesicles (A) X4000, (B) X 20000 . 


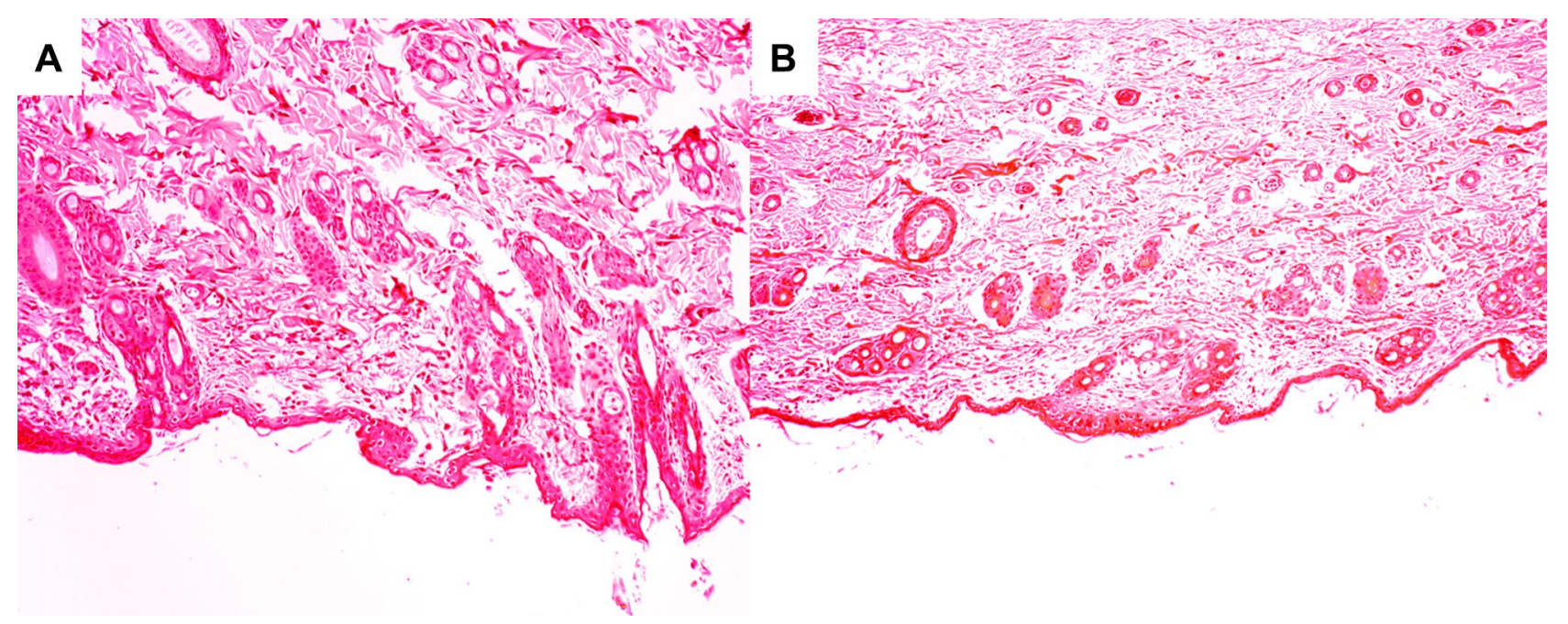

Figure 6 Histopathological examination of rabbit back skin untreated (control) (A) and treated with lyophilized nanovesicular gel (B) after treatment for three days (XI00).

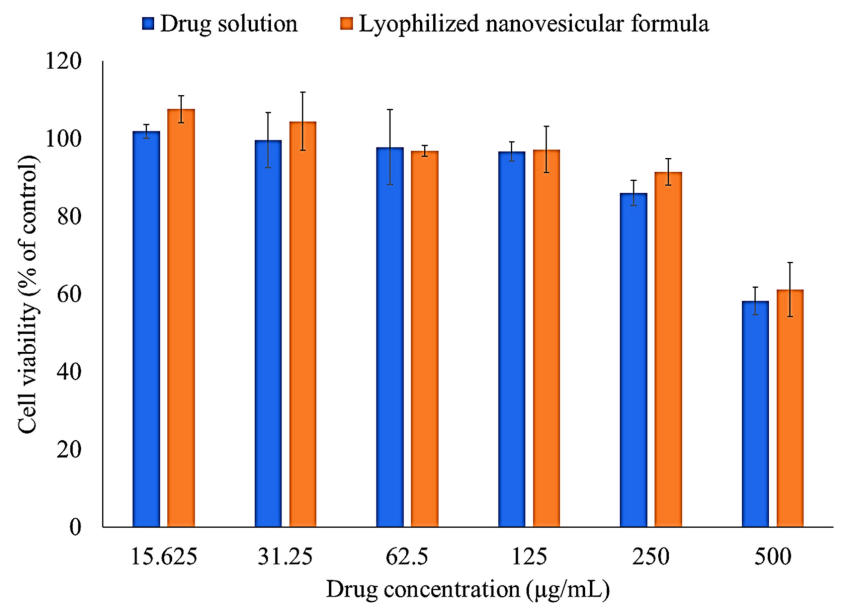

Figure 7 Cytotoxicity assay of ivabradine (drug solution and lyophilized nanovesicular gel) on HepG2 cells at different concentrations (I5.625 to $500 \mu \mathrm{g} / \mathrm{mL}$ at $24 \mathrm{~h}$ ), compared to respective untreated cells used as control.

with Ahmed et al who studied the cytotoxic effect of halloysite nanotubes against HepG2, their results also declared the safety of the used nanotubes up to $125 \mu \mathrm{g} /$ $\mathrm{mL}$ with a further decrease in safety upon the increase of concentration to 250 and $500 \mu \mathrm{g} / \mathrm{mL} .{ }^{39}$

\section{Oral and Transdermal Bioavailability of Ivabradine}

The in vivo profiles of ivabradine after oral administration of the optimized formula and transdermal application of the nanovesicular gel to rabbits, compared to the market product (Procoralan ${ }^{\circledR}$ ) are presented in Figure 8. The pharmacokinetic parameters are also shown in Table 3 . The orally administered optimized formula showed a significant increase in the drug bioavailability (254.61\%) when compared to the market product. These results are in line with Varshozaz et al who tried to encapsulate the water-soluble drug buspirone $\mathrm{HCl}$ in solid lipid nanoparticles. ${ }^{71}$ Their optimized formula entrapped $\approx 32.8 \%$ of the drug with an increase in bioavailability that reached 2.53 folds in comparison to buspirone solution. This could be attributed to the avoidance of the hepatic 1st pass effect through enhancing the lymphatic uptake as previously reported by Elsayed et al and Baek et al. ${ }^{16,72}$ A similar bioavailability enhancement (185.22\%) was observed upon transdermal application of the nanovesicular gel. This might be referred to the small nanovesicular size $(<300 \mathrm{~nm})$ and the presence of PL and SP as surfactants that could solubilize intercellular lipids and increase the fluidity of the stratum corneum layer, in addition to disrupting corneocytes because of the possible interaction with keratin filaments. ${ }^{73,74}$ On the other hand, the pharmacokinetic data depicted in Table 3 indicated a significant increase in $\mathrm{C}_{\max }$ of ivabradine nanovesicles either as an oral lyophilized product or as a transdermal gel $(\mathrm{p}<0.05)$ in comparison to market product. These results are in accordance with the results declared by Yaghoobian et al who fabricated repaglinide niosomes using different surfactants. ${ }^{75}$ All the engineered niosomes showed higher $\mathrm{C}_{\max }$ in comparison to the drug suspension. ${ }^{76}$ Also, it is worth noticing that the developed nanovesicles could successfully increase ivabradine half-life from $2.88 \pm 0.73 \mathrm{~h}$ for the market product to $6.6 \pm$ 


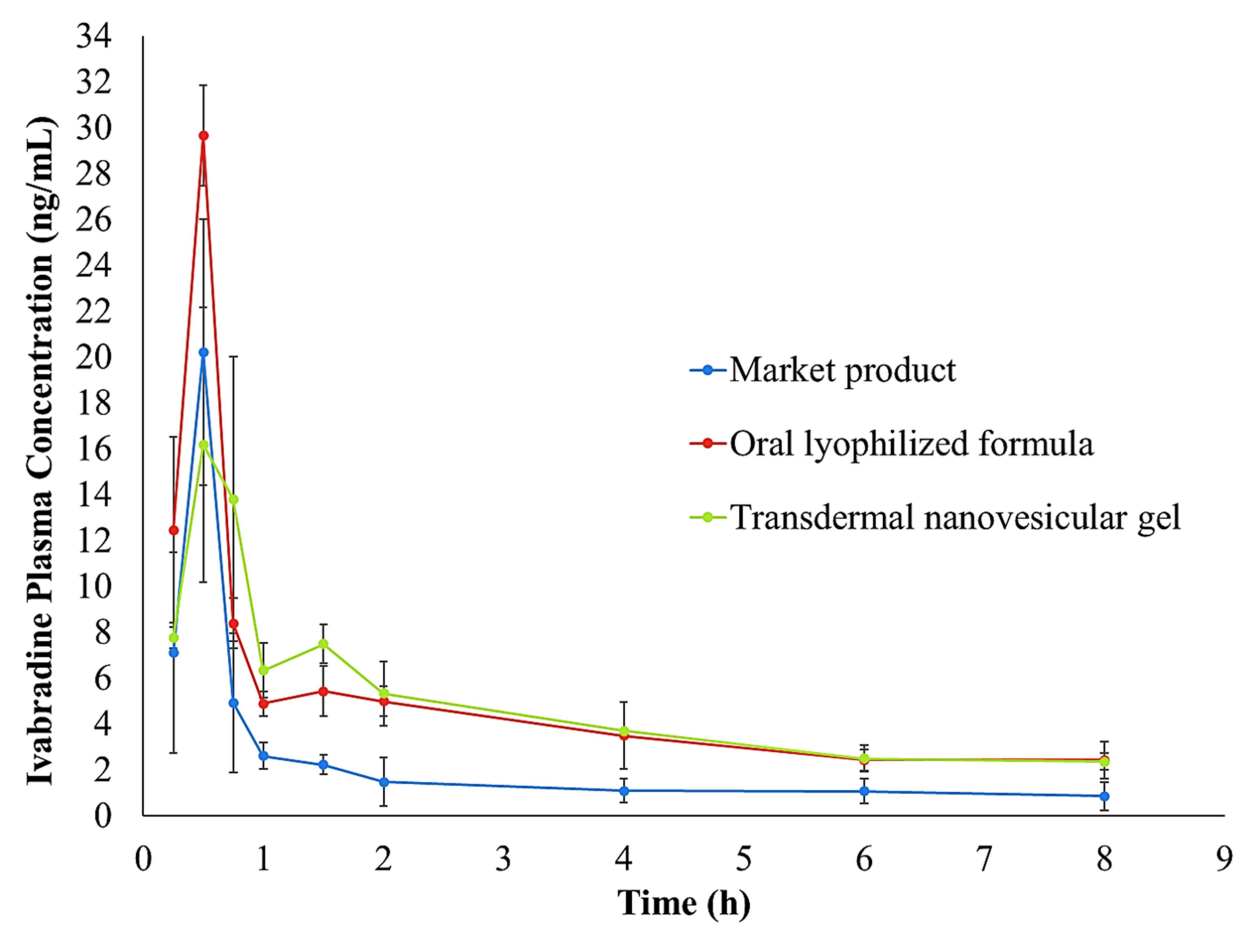

Figure 8 Mean plasma concentrations $(\mathrm{ng} / \mathrm{mL})$ of ivabradine after oral administration of the lyophilized formula and transdermal application of the nanovesicular gel, compared to the marketed product (Procoralan ${ }^{\circledR}$ ).

Table 3 Pharmacokinetic Parameters of Ivabradine After Oral and Transdermal Administration of Lyophilized Nanovesicles and Nanovesicular Gel to Rabbits, Compared to the Market Oral Tablets (Procoralan ${ }^{\circledR}$ ) ${ }^{\text {a,b }}$

\begin{tabular}{|c|c|c|c|}
\hline $\begin{array}{l}\text { Pharmacokinetic } \\
\text { Parameters }\end{array}$ & $\begin{array}{c}\text { The } \\
\text { Market } \\
\text { Product }\end{array}$ & $\begin{array}{l}\text { The Oral } \\
\text { Optimized } \\
\text { Formula }\end{array}$ & $\begin{array}{c}\text { The } \\
\text { Transdermal } \\
\text { Nanovesicular } \\
\text { Gel }\end{array}$ \\
\hline$K\left(h^{-1}\right)$ & $\begin{array}{c}0.36 \pm \\
0.01\end{array}$ & $0.10 \pm 0.01$ & $0.08 \pm 0.02$ \\
\hline$T_{1 / 2}\left(h^{-1}\right)$ & $\begin{array}{c}2.88 \pm \\
0.73\end{array}$ & $6.60 \pm 0.11$ & $8.02 \pm 0.34$ \\
\hline$T_{\max }(h)^{c}$ & 0.75 & 0.5 & 0.5 \\
\hline $\mathrm{C}_{\max }(\mathrm{ng} / \mathrm{mL})$ & $\begin{array}{l}16.11 \\
\pm 1.57\end{array}$ & $29.66 \pm 1.90$ & $20.43 \pm 1.28$ \\
\hline $\mathrm{AUC}_{0-8}(\mathrm{ng} \cdot \mathrm{h} / \mathrm{mL})$ & $\begin{array}{c}22.00 \pm \\
1.84\end{array}$ & $38.60 \pm 2.77$ & $39.22 \pm 2.01$ \\
\hline$A \cup C_{0-\infty}(\mathrm{ng} . \mathrm{h} / \mathrm{mL})$ & $\begin{array}{r}23.29 \\
\pm 1.59\end{array}$ & $59.30 \pm 3.25$ & $43.14 \pm 1.94$ \\
\hline $\begin{array}{l}\text { Relative } \\
\text { bioavailability (\%) }\end{array}$ & - & 254.61 & 185.22 \\
\hline
\end{tabular}

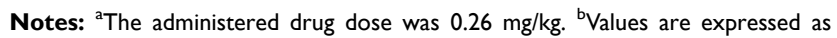
mean $\pm S D ; n=9$. ${ }^{~ M e d i a n ~ o f ~} T_{\max }$ is displayed instead of the mean values.

$0.11 \mathrm{~h}$ in the case of oral optimized formula and 8.02 $\pm 0.34 \mathrm{~h}$ for the transdermal vesicles $(\mathrm{p}<0.05)$. These results coincide with the in vitro release profile of the drug and also with the in vivo results declared by
Ramkanth et al who tried to formulate atenolol niosomes for transdermal administration, their results showed a higher drug bioavailability with prolonged $\mathrm{T}_{1 / 2}{ }^{77,78}$

\section{Conclusions}

The optimized nanovesicles were capable of doubling ivabradine bioavailability either after oral administration of its lyophilizate or transdermal application of its carbopol gel. The orally administered optimized formula was able to avoid the hepatic $1^{\text {st }}$ pass effect while the transdermally applied nanovesicular gel was capable to penetrate deeply through the skin layer and reaching the bloodstream. Having the same formula tailored for both oral and transdermal administration could be considered a promising costeffective approach for industrial applications. Future work may consider trying the same formula as a platform for bioavailability enhancement of other active ingredients highly susceptible to hepatic $1^{\text {st }}$ pass metabolism.

\section{Acknowledgment}

The authors would like to thank Cell Culture unit Laboratory, Faculty of Pharmacy, October 6 University, Giza, Egypt for their contribution in the in vitro cytotoxicity study. 


\section{Disclosure}

The authors report no conflicts of interest in this work.

\section{References}

1. Swedberg K, Komajda M, Böhm M, et al. Ivabradine and outcomes in chronic heart failure (SHIFT): a randomised placebo-controlled study. Lancet. 2010;376(9744):875-885. doi:10.1016/S01406736(10)61198-1

2. Tse S, Mazzola N. Ivabradine (corlanor) for heart failure: the first selective and specific If inhibitor. Pharm Ther. 2015;40(12):810.

3. Thorup L, Simonsen U, Grimm D, Hedegaard ER. Ivabradine: current and future treatment of heart failure. Basic Clin Pharmacol Toxicol. 2017;121(2):89-97. doi:10.1111/bcpt.12784

4. Eid H, Darweesh E, Sabri NA. Ivabradine in Chronic Heart Failure. Arch Pharm Sci Ain Shams Univ. 2020;4(1):36-46.

5. Pei H, Miao W, Xie W-Z, et al. Ivabradine improves cardiac function and increases exercise capacity in patients with chronic heart failure. Int Heart J. 2019;18-559.

6. Balata GF, Faisal MM, Elghamry HA, Sabry SA. Preparation and Characterization of Ivabradine $\mathrm{HCl}$ Transfersomes for Enhanced Transdermal Delivery. J Drug Deliv Sci Technol. 2020;60:101921. doi:10.1016/j.jddst.2020.101921

7. Rosa GM, Ferrero S, Ghione P, Valbusa A, Brunelli C. An evaluation of the pharmacokinetics and pharmacodynamics of ivabradine for the treatment of heart failure. Expert Opin Drug Metab Toxicol. 2014;10 (2):279-291. doi:10.1517/17425255.2014.876005

8. Sattar Y, Samani EN, Zafrullah FNU, Latchana S, Patel NB. Ivabradine in congestive heart failure: patient selection and perspectives. Cureus. 2019;11:4.

9. Majeed A, Ranjha NM, Hussain M, Rasool MF. Fabrication and evaluation of $\mathrm{pH}$-dependent polymeric microspheres of ivabradine and their in vitro and in vivo studies. Polym Bull. 2019;76 (6):3127-3151. doi:10.1007/s00289-018-2546-0

10. Qumber M, Alruwaili NK, Bukhari SNA, et al. BBD-based development of itraconazole loaded nanostructured lipid carrier for topical delivery: in vitro evaluation and antimicrobial assessment. $J$ Pharm Innov. 2020;1-14.

11. Imam SS, Ahad A, Aqil M, Akhtar M, Sultana Y, Ali A. Formulation by design based risperidone nano soft lipid vesicle as a new strategy for enhanced transdermal drug delivery: in-vitro characterization, and in-vivo appraisal. Mater Sci Eng C. 2017;75:1198-1205. doi:10.1016/j.msec.2017.02.149

12. Patel G, Thakkar VT, Dudhat KH. Optimization of ivabradine hydrochloride transdermal patch by D-optimal mixture design: in vitro and in vivo evaluation. Curr Drug Ther. 2017;12(2):149-162. doi: $10.2174 / 1574885512666170606115828$

13. Banu TS, Sandhya KV, Jayaveera KN. Formulation and evaluation of transdermal drug delivery systems of ivabradine hydrochloride. Res J Pharm Technol. 2014;7(1):1-7.

14. Lodhi M, Dubey A, Narayan R, Prabhu P, Priya S. Formulation and evaluation of buccal film of Ivabradine hydrochloride for the treatment of stable angina pectoris. Int J Pharm Investig. 2013;3(1):47. doi:10.4103/2230-973X.108963

15. Mishra A, Imam SS, Aqil M, et al. Carvedilol nano lipid carriers: formulation, characterization and in-vivo evaluation. Drug Deliv. 2016;23(4):1486-1494. doi:10.3109/10717544.2016.1165314

16. Elsayed I, El-Dahmy RM, Elshafeey AH, et al. Tripling the bioavailability of rosuvastatin calcium through development and optimization of an in-situ forming nanovesicular system. Pharmaceutics. 2019;11 (6):275. doi:10.3390/pharmaceutics 11060275

17. Omar MM, Hasan OA, El Sisi AM. Preparation and optimization of lidocaine transferosomal gel containing permeation enhancers: a promising approach for enhancement of skin permeation. Int J Nanomedicine. 2019;14:1551. doi:10.2147/IJN.S201356
18. Qumbar M, Imam SS, Ali J, Ahmad J, Ali A. Formulation and optimization of lacidipine loaded niosomal gel for transdermal delivery: in-vitro characterization and in-vivo activity. Biomed Pharmacother. 2017;93:255-266. doi:10.1016/j.biopha.2017.06.043

19. Thakur RK, Sharma D, Singh KK. Optimization of surface roughness and delamination factor in end milling of graphene modified GFRP using response surface methodology. Mater Today Proc. 2019;19:133-139. doi:10.1016/j.matpr.2019.06.153

20. Shojaei S, Shojaei S. Optimization of process variables by the application of response surface methodology for dye removal using nanoscale zero-valent iron. Int $J$ Environ Sci Technol. 2019;16 (8):4601-4610. doi:10.1007/s13762-018-1866-9

21. Hussain G, Haydar S. Exploring potential of pearl millet (Pennisetum glaucum) and black-eyed pea (Vigna unguiculata subsp. unguiculata) as bio-coagulants for water treatment. Desalin Water Treat. 2019;143:184-191. doi:10.5004/dwt.2019.23255

22. Kahraman MF, Bilge H, Öztürk S. Uncertainty analysis of milling parameters using Monte Carlo simulation, the Taguchi optimization method and data-driven modeling. Mater Test. 2019;61(5):477-483. doi:10.3139/120.111344

23. Emad Eldeeb A, Salah S, Ghorab M. Proniosomal gel-derived niosomes: an approach to sustain and improve the ocular delivery of brimonidine tartrate; formulation, in-vitro characterization, and in-vivo pharmacodynamic study. Drug Deliv. 2019;26(1):509-521. doi:10.1080/10717544.2019.1609622

24. Sohail MF, Shahnaz G, Ur Rehman F, et al. Development and evaluation of optimized thiolated chitosan proniosomal gel containing duloxetine for intranasal delivery. AAPS PharmSciTech. 2019;20 (7):288. doi:10.1208/s12249-019-1484-y

25. Naguib MJ, Salah S, Halim SAA, Badr-Eldin SM. Investigating the potential of utilizing glycerosomes as a novel vesicular platform for enhancing intranasal delivery of lacidipine. Int $J$ Pharm. 2020;582:119302. doi:10.1016/j.ijpharm.2020.119302

26. Paterakis PG, Korakianiti ES, Dallas PP, Rekkas DM. Evaluation and simultaneous optimization of some pellets characteristics using a 33 factorial design and the desirability function. Int $J$ Pharm. 2002;248 (1-2):51-60. doi:10.1016/S0378-5173(02)00341-1

27. Yasir M, Sara UVS, Chauhan I, et al. Solid lipid nanoparticles for nose to brain delivery of donepezil: formulation, optimization by Box-Behnken design, in vitro and in vivo evaluation. Artif Cells Nanomed Biotechnol. 2018;46(8):1838-1851.

28. Hashad RA, Ishak RAH, Fahmy S, Mansour S, Geneidi AS. Chitosan-tripolyphosphate nanoparticles: optimization of formulation parameters for improving process yield at a novel $\mathrm{pH}$ using artificial neural networks. Int J Biol Macromol. 2016;86:50-58. doi:10.1016/j. ijbiomac.2016.01.042

29. Yu H, Teo J, Chew JW, Hadinoto K. Dry powder inhaler formulation of high-payload antibiotic nanoparticle complex intended for bronchiectasis therapy: spray drying versus spray freeze drying preparation. Int J Pharm. 2016;499(1-2):38-46. doi:10.1016/j.ijpharm.2015.12.072

30. Tran -T-T, Amalina N, Cheow WS, Hadinoto K. Effects of storage on the stability and aerosolization efficiency of dry powder inhaler formulation of plasmid DNA-chitosan nanoparticles. J Drug Deliv Sci Technol. 2020;59:101866. doi:10.1016/j.jddst.2020.101866

31. Khurana B, Arora D, Narang RK. QbD based exploration of resveratrol loaded polymeric micelles based carbomer gel for topical treatment of plaque psoriasis: in vitro, ex vivo and in vivo studies. $J$ Drug Deliv Sci Technol. 2020;59:101901. doi:10.1016/j.jddst.2020.101901

32. Chu JS, Danny MY, Amidon GL, Weiner ND, Goldberg AH. Viscoelastic properties of polyacrylic acid gels in mixed solvents. Pharm Res. 1992;9(12):1659-1663. doi:10.1023/A:1015841214591

33. Tareen FK, Shah KU, Ahmad N, Ur Rehman A, Shah SU, Ullah N. Proniosomes as a Carrier System for Transdermal Delivery of Clozapine. Drug Dev Ind Pharm. 2020;1-24. doi:10.1080/ 03639045.2020.1764020 
34. Alruwaili NK, Imam SS, Alotaibi $\mathrm{NH}$, et al. Formulation of chitosan polymeric vesicles of ciprofloxacin for ocular delivery: box-behnken optimization, in vitro characterization, HET-CAM irritation, and antimicrobial assessment. AAPS PharmSciTech. 2020;21:1-16.

35. Melo CM, Cardoso JF, Perassoli FB, et al. Amphotericin b-loaded Eudragit RL100 nanoparticles coated with hyaluronic acid for the treatment of vulvovaginal candidiasis. Carbohydr Polym. 2020;230:115608. doi:10.1016/j.carbpol.2019.115608

36. Nour SA, Abdelmalak NS, Naguib MJ, Rashed HM, Ibrahim AB. Intranasal brain-targeted clonazepam polymeric micelles for immediate control of status epilepticus: in vitro optimization, ex vivo determination of cytotoxicity, in vivo biodistribution and pharmacodynamics studies. Drug Deliv. 2016;23(9):3681-3695. doi:10.1080/10717544.2016.1223216

37. Amer SS, Nasr M, Abdel-Aziz RTA, et al. Cosm-nutraceutical nanovesicles for acne treatment: physicochemical characterization and exploratory clinical experimentation. Int $J$ Pharm. 2020;577:119092. doi:10.1016/j.ijpharm.2020.119092

38. Fayyaz A, Ranta V-P, Toropainen E, et al. Topical ocular pharmacokinetics and bioavailability for a cocktail of atenolol, timolol and betaxolol in rabbits. Eur J Pharm Sci. 2020;155:105553. doi:10.1016/ j.ejps.2020.105553

39. Ahmed FR, Shoaib MH, Azhar M, et al. In-vitro assessment of cytotoxicity of halloysite nanotubes against HepG2, HCT116 and human peripheral blood lymphocytes. Colloids Surf B Biointerfaces. 2015;135:50-55. doi:10.1016/j.colsurfb.2015.07.021

40. Clark JD, Gebhart GF, Gonder JC, Keeling ME, Kohn DF. The 1996 guide for the care and use of laboratory animals. ILAR J. 1997;38 (1):41-48. doi:10.1093/ilar.38.1.41

41. Raza A, Hayat U, Wang H-J, Wang J-Y. Preparation and evaluation of captopril loaded gastro-retentive zein based porous floating tablets. Int J Pharm. 2020;579:119185. doi:10.1016/j.ijpharm.2020.119185

42. Nair A, Jacob S. A simple practice guide for dose conversion between animals and human. J Basic Clin Pharm. 2016;7(2):27. doi:10.4103/0976-0105.177703

43. Osborne J. Improving your data transformations: applying the Box-Cox transformation. Pract Assess Res Eval. 2010;15(1):12.

44. Ashri LY, Amal El Sayeh F, Ibrahim MA, Alshora DH, Naguib MJ. Optimization and evaluation of chitosan buccal films containing tenoxicam for treating chronic periodontitis: in vitro and in vivo studies. J Drug Deliv Sci Technol. 2020;57:101720. doi:10.1016/j. jddst.2020.101720

45. Wang M, You S-K, Lee H-K, et al. Development and evaluation of docetaxel-phospholipid complex loaded self-microemulsifying drug delivery system: optimization and in vitro/ex vivo studies. Pharmaceutics. 2020;12(6):544. doi:10.3390/pharmaceutics 12060544

46. Visetvichaporn V, Kim K-H, Jung K, Cho Y-S, Kim -D-D. Formulation of self-microemulsifying drug delivery system (SMEDDS) by D-optimal mixture design to enhance the oral bioavailability of a new cathepsin K inhibitor (HL235). Int J Pharm. 2020;573:118772. doi:10.1016/j.ijpharm.2019.118772

47. Hayashi K, Shimanouchi T, Kato K, Miyazaki T, Nakamura A, Umakoshi H. Span 80 vesicles have a more fluid, flexible and "wet" surface than phospholipid liposomes. Colloids Surf B Biointerfaces. 2011;87(1):28-35. doi:10.1016/j.colsurfb. 2011.04.029

48. Allotey-Babington GL, Nettey H, D'Sa S, Gomes KB, D’Souza MJ. Cancer chemotherapy: effect of poloxamer modified nanoparticles on cellular function. J Drug Deliv Sci Technol. 2018;47:181-192. doi:10.1016/j.jddst.2018.06.012

49. Zhang Y, Lam YM. Controlled synthesis and association behavior of graft Pluronic in aqueous solutions. J Colloid Interface Sci. 2007;306 (2):398-404. doi:10.1016/j.jcis.2006.10.073
50. Ogunsola OA, Kraeling ME, Zhong S, Pochan DJ, Bronaugh RL, Raghavan SR. Structural analysis of "flexible" liposome formulations: new insights into the skin-penetrating ability of soft nanostructures. Soft Matter. 2012;8(40):10226-10232. doi:10.1039/ c2sm26614h

51. Shakeri M, Razavi SH, Shakeri S. Carvacrol and astaxanthin co-entrapment in beeswax solid lipid nanoparticles as an efficient nano-system with dual antioxidant and anti-biofilm activities. $L W T$. 2019;107:280-290. doi:10.1016/j.1wt.2019.03.031

52. Yoon R-H, Yordan JL. Zeta-potential measurements on microbubbles generated using various surfactants. J Colloid Interface Sci. 1986;113 (2):430-438. doi:10.1016/0021-9797(86)90178-5

53. Sharma V, Dewangan HK, Maurya L, Vats K, Verma H. Rational design and in-vivo estimation of Ivabradine Hydrochloride loaded nanoparticles for management of stable angina. J Drug Deliv Sci Technol. 2019;54:101337. doi:10.1016/j.jddst.2019.101337

54. Valissery P, Thapa R, Singh J, et al. Potent in vivo antimalarial activity of water-soluble artemisinin nano-preparations. RSC Adv. 2020;10(59):36201-36211. doi:10.1039/D0RA05597B

55. Ibrahim AH, Smått J-H, Govardhanam NP, et al. Formulation and optimization of drug-loaded mesoporous silica nanoparticle-based tablets to improve the dissolution rate of the poorly water-soluble drug silymarin. Eur J Pharm Sci. 2020;142:105103. doi:10.1016/j. ejps.2019.105103

56. Maraldi M, Ferrari R, Auriemma R, Sponchioni M, Moscatelli D. Concentration of polymer nanoparticles through dialysis: efficacy and comparison with lyophilization for PEGylated and zwitterionic systems. J Pharm Sci. 2020;109(8):2607-2614. doi:10.1016/j. xphs.2020.05.001

57. Date PV, Samad A, Devarajan PV. Freeze thaw: a simple approach for prediction of optimal cryoprotectant for freeze drying. AAPS Pharmscitech. 2010;11(1):304-313. doi:10.1208/s12249-010-9382-3

58. Campos JR, Fernandes AR, Sousa R, et al. Optimization of nimesulide-loaded solid lipid nanoparticles (SLN) by factorial design, release profile and cytotoxicity in human Colon adenocarcinoma cell line. Pharm Dev Technol. 2019;24(5):616-622. doi:10.1080/ 10837450.2018.1549075

59. Siri M, Grasselli M, Alonso SDV. Albumin-based nanoparticle trehalose lyophilisation stress-down to preserve structure/function and enhanced binding. $J$ Pharm Biomed Anal. 2016;126:66-74. doi:10.1016/j.jpba.2016.04.037

60. Bosch S, De Beaurepaire L, Allard M, et al. Trehalose prevents aggregation of exosomes and cryodamage. Sci Rep. 2016;6(1):1-11. doi: $10.1038 /$ srep36162

61. Cortada-Garcia M, Dore V, Mazzei L, Angeli P. Experimental and CFD studies of power consumption in the agitation of highly viscous shear thinning fluids. Chem Eng Res Des. 2017;119:171-182. doi:10.1016/j.cherd.2017.01.018

62. Alruwaili NK, Zafar A, Imam SS, et al. Stimulus responsive ocular gentamycin-ferrying chitosan nanoparticles hydrogel: formulation optimization, ocular safety and antibacterial assessment. Int J Nanomedicine. 2020;15:4717. doi:10.2147/IJN.S254763

63. Carvalho FC, Calixto G, Hatakeyama IN, Luz GM, Gremião MPD, Chorilli M. Rheological, mechanical, and bioadhesive behavior of hydrogels to optimize skin delivery systems. Drug Dev Ind Pharm. 2013;39(11):1750-1757. doi:10.3109/03639045.2012.734510

64. Ellaithy HM, El-Shaboury KMF. The development of Cutina lipogels and gel microemulsion for topical administration of fluconazole. AAPS Pharmscitech. 2002;3(4):77-85. doi:10.1208/pt030435

65. Elkhoury K, Koçak P, Kang A, Arab-Tehrany E, Ellis Ward J, Shin SR. Engineering smart targeting nanovesicles and their combination with hydrogels for controlled drug delivery. Pharmaceutics. 2020;12(9):849. doi:10.3390/pharmaceutics 12090849

66. Mukherjee B, Patra B, Layek B, Mukherjee A. Sustained release of acyclovir from nano-liposomes and nano-niosomes: an in vitro study. Int J Nanomedicine. 2007;2(2):213. 
67. Abdelnabi DM, Abdallah MH, Elghamry HA. Buspirone hydrochloride loaded in situ nanovesicular gel as an anxiolytic nasal drug delivery system: in vitro and animal studies. AAPS PharmSciTech. 2019;20(3):134. doi:10.1208/s12249-018-1211-0

68. Kumar Gaur P, Mishra S, Purohit S. Nanovesicles of nitrendipine with lipid complex for transdermal delivery: pharmacokinetic and pharmacodynamic studies. Artif Cells Nanomed Biotechnol. 2016;44 (7):1684-1693. doi:10.3109/21691401.2015.1080170

69. Soliman SM, Abdelmalak NS, El-Gazayerly ON, Abdelaziz N. Novel non-ionic surfactant proniosomes for transdermal delivery of lacidipine: optimization using 23factorial design and in vivo evaluation in rabbits. Drug Deliv. 2016;23(5):1608-1622. doi:10.3109/ 10717544.2015.1132797

70. El-Ridy MS, Yehia SA, Elsayed I, Younis MM, Abdel-Rahman F. Metformin hydrochloride and wound healing: from nanoformulation to pharmacological evaluation. J Liposome Res. 2019;1-14.

71. Varshosaz J, Tabbakhian M, Mohammadi MY. Formulation and optimization of solid lipid nanoparticles of buspirone $\mathrm{HCl}$ for enhancement of its oral bioavailability. J Liposome Res. 2010;20(4):286-296. doi: $10.3109 / 08982100903443065$

72. Baek J-S, Cho C-W. Surface modification of solid lipid nanoparticles for oral delivery of curcumin: improvement of bioavailability through enhanced cellular uptake, and lymphatic uptake. Eur J Pharm Biopharm. 2017;117:132-140. doi:10.1016/j.ejpb.2017.04.013
73. Som I, Bhatia K, Yasir M. Status of surfactants as penetration enhancers in transdermal drug delivery. J Pharm Bioallied Sci. 2012;4(1):2. doi:10.4103/0975-7406.92724

74. Elsherif NI, Shamma RN, Abdelbary G. Terbinafine hydrochloride trans-ungual delivery via nanovesicular systems: in vitro characterization and ex vivo evaluation. AAPS PharmSciTech. 2017;18 (2):551-562. doi:10.1208/s12249-016-0528-9

75. Yaghoobian M, Haeri A, Bolourchian N, Shahhosseni S, Dadashzadeh S. The impact of surfactant composition and surface charge of niosomes on the oral absorption of repaglinide as a BCS II model drug. Int J Nanomedicine. 2020;15:8767. doi:10.2147/IJN. S261932

76. Imam SS, Aqil M, Akhtar M, Sultana Y, Ali A. Formulation by design-based proniosome for accentuated transdermal delivery of risperidone: in vitro characterization and in vivo pharmacokinetic study. Drug Deliv. 2015;22(8):1059-1070. doi:10.3109/ 10717544.2013.870260

77. Ramkanth S, Chetty CM, Sudhakar Y, Thiruvengadarajan VS, Anitha P, Gopinath C. Development, characterization \& invivo evaluation of proniosomal based transdermal delivery system of Atenolol. Futur J Pharm Sci. 2018;4(1):80-87.

78. Afzal M, Alharbi KS, Alruwaili NK, et al. Nanomedicine in treatment of breast cancer-A challenge to conventional therapy. In: Seminars in Cancer Biology; 2019: Elsevier.
International Journal of Nanomedicine

\section{Publish your work in this journal}

The International Journal of Nanomedicine is an international, peerreviewed journal focusing on the application of nanotechnology in diagnostics, therapeutics, and drug delivery systems throughout the biomedical field. This journal is indexed on PubMed Central, MedLine, CAS, SciSearch ${ }^{\circledR}$, Current Contents ${ }^{\circledR} /$ Clinical Medicine,
Dovepress

Journal Citation Reports/Science Edition, EMBase, Scopus and the Elsevier Bibliographic databases. The manuscript management system is completely online and includes a very quick and fair peer-review system, which is all easy to use. Visit http://www.dovepress.com/ testimonials.php to read real quotes from published authors. 